Supporting information for

\title{
The Effect of Antifreeze Proteins on the Nucleation, Growth and the Memory Effect During Tetrahydrofuran Clathrate Hydrate Formation
}

The curves of $N_{\mathrm{t}} / N_{0}(\mathrm{y})$ vs time ( $\left.\mathrm{t}\right)$ are fit as $N_{\mathrm{t}} / N_{0}=(1-A)+A \exp \left(-t / t_{1}\right)$ where $A$ represents the fraction of samples that showed hydrate formation during the observation period and $t_{1}$ represents the average lag time. The fitting results are listed in Table 1.

An example is given below. It is PVP-THF- $\mathrm{H}_{2} \mathrm{O}(0.25 \mathrm{mM})$ at $273 \mathrm{~K}$.

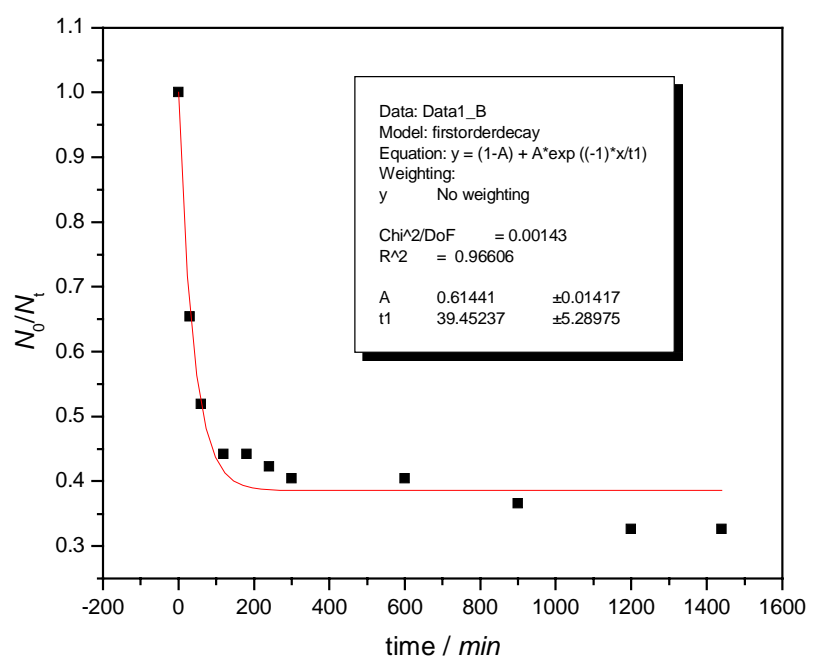

Table 1. Fraction of samples that formed hydrate $(A)$ and average lag time $\left(t_{1}\right)$ for THF hydrate formation in bulk solution at $273 \mathrm{~K}$, derived from induction time experiments ${ }^{\text {a }}$. The melted sample was melted at $279.5 \mathrm{~K}$ for $1 \mathrm{~h}$ before isothermal at $273 \mathrm{~K}$. 


\begin{tabular}{|c|c|c|c|c|c|c|}
\hline Hydrate type & $A$ & $t_{1} / \mathrm{min}$ & $A / A_{\mathrm{THF}}$ & $t_{1} / t_{1 \mathrm{THF}}$ & $A_{\mathrm{f}} / A_{\mathrm{m}}$ & $t_{1 f} / t_{1 m}$ \\
\hline $\begin{array}{l}\text { THF } \\
\text { melted }\end{array}$ & $\begin{array}{ll}0.89 & (0.07) \\
0.92 & (0.07) \\
\end{array}$ & \begin{tabular}{|l|}
$51(10)$ \\
$8(2)$
\end{tabular} & --- & -- & $0.97(0.15)$ & $6.38(1.50)$ \\
\hline $\begin{array}{l}\text { PVP } \\
\begin{array}{r}(0.25 \mathrm{mM}) \\
\text { melted }\end{array}\end{array}$ & $\begin{array}{ll}0.61 & (0.01) \\
0.94 & (0.02) \\
\end{array}$ & $\begin{array}{l}40(5) \\
16(3)\end{array}$ & $0.69(0.09)$ & $0.78(0.29)$ & $0.65(0.03)$ & $2.50(0.50)$ \\
\hline $\begin{array}{l}\text { PVP } \\
\begin{array}{l}(0.05 \mathrm{mM}) \\
\quad \text { melted }\end{array}\end{array}$ & $\begin{array}{ll}0.89 & (0.04) \\
0.88 & (0.07)\end{array}$ & $\begin{array}{l}15(1) \\
6(1)\end{array}$ & $1.00(0.12)$ & $0.29(0.22)$ & $1.01(0.13)$ & $2.50(0.33)$ \\
\hline $\begin{array}{l}\text { Cyto C } \\
(0.25 \mathrm{mM}) \\
\text { melted }\end{array}$ & $\begin{array}{l}0.94(0.08) \\
0.99(0.05) \\
\end{array}$ & \begin{tabular}{|l|}
$68(14)$ \\
$25(4)$ \\
\end{tabular} & $1.06(0.17)$ & $1.33(0.47)$ & $0.95(0.13)$ & $2.72(0.72)$ \\
\hline $\begin{array}{l}\text { wfAFP } \\
(0.25 \mathrm{mM}) \\
\text { melted }\end{array}$ & $\begin{array}{l}0.48(0.02) \\
0.49(0.04)\end{array}$ & $\begin{array}{l}191(37) \\
155(42) \\
\end{array}$ & $0.54(0.10)$ & $3.75(0.92)$ & $0.98(0.12)$ & $1.23(0.51)$ \\
\hline $\begin{array}{l}\text { wfAFP } \\
(0.05 \mathrm{mM}) \\
\quad \text { melted }\end{array}$ & $\begin{array}{l}0.86(0.04) \\
0.97(0.03)\end{array}$ & $\begin{array}{l}177(26) \\
16(2)\end{array}$ & $0.97(0.12)$ & $3.47(0.71)$ & $0.89(0.07)$ & $11.06(1.75)$ \\
\hline $\begin{array}{l}\text { CfAFP } \\
(0.05 \mathrm{mM}) \\
\text { melted }\end{array}$ & $\begin{array}{l}0.68(0.08) \\
0.70(0.08)\end{array}$ & $\begin{array}{l}290(90) \\
265(84)\end{array}$ & $0.76(0.17)$ & $5.69(1.96)$ & $0.97(0.23)$ & $1.09(0.65)$ \\
\hline
\end{tabular}

a. Data are fit as $N_{\mathrm{t}} / N_{0}=(1-A)+A \exp \left(-t / t_{1}\right)$. A was the fraction of samples that showed hydrate formation during the observation period; $t_{1}$ represents the average lag time of the transition;

The table shows:

$A / A_{\mathrm{THF}}$ value. A smaller value represents stronger inhibition activity.

$t_{1} / t_{1 \mathrm{THF}}$ : A ratio smaller than 1 indicates nucleation activity while the values greater than one indicates inhibition of nucleation.

$A_{\mathrm{f}} / A_{\mathrm{m}}$ value. This indicates the effect of melting on the fraction of samples that formed hydrate during the observation period. The smaller ratio represents a larger effect.

$t_{1 f} / t_{1 m}$ : the ratio of the lag times for fresh and melted samples; values near 1 indicate a lack of the memory effect; the larger the value, the greater the memory effect. 